\title{
SUPERMAT- A virtual Center for sustainable development of Advanced Materials operating under extreme conditions
}

\author{
Authors: Radu R. Piticescu*,1, Santiago Cuesta-Lopez², Antonio Rinaldi ${ }^{3}$, Marina Urbina ${ }^{4}$, Yi Qinn $^{5}$, Peter \\ Szakalos $^{6}$, Alain Largeteau ${ }^{7}$
}

\author{
${ }^{1}$ National R\&D Institute for Nonferrous and Rare Metals-IMNR, 102 Biruintei Blvd, 077145 Pantelimon-Ilfov, Romania \\ ${ }^{2}$ University of Burgos, International Research Centre in Critical Raw Materials-ICCRAM, Science and Technology Park, Plaza \\ Misael Banuelos s/n, 09001 Burgos, Spain \\ ${ }^{3}$ Agenzia Nazionale per le Nuove Technologie, l'Energia e lo Sviluppo Economico Sostenabile-ENEA, Casaccia Research \\ Centre, Via Anguillarese 301, 00123 Rome, Italy \\ ${ }^{4}$ Commisariat à l'Energie Atomique et aux Energies Alternatives, Laboratoire d'Innovation pour les Technologies des Energies \\ Nouvelles CEA-LITEN, , 17 Rue des Martyrs, 38054 Grenoble, Cedex 9, France \\ ${ }^{5}$ The University of Strathclyde, Department of Design, Manufacture and Engineering Management, 75 Montrose Str., Glasgow \\ G1 1XJ, UK \\ ${ }^{6}$ Kungliga Tekniska Hoegskolan, Brinellvagen 8, SE-10044, Stockholm, Sweden \\ ${ }^{7}$ CNRS, Insititut de Chimie de la Matitere Condensee de Bordeaux-ICMCB, 87 Av. du Dr. Albert Schweitzer, F-33608 Pessac \\ Cedex, France
}

\begin{abstract}
The expertise, main experimental facilities and some selected results of the EU SUPERMAT Consortium are described, showing the importance of integrating modelling and simulation, fast sintering and coating technologies and specific characterisation techniques for obtaining high temperature ceramics, oxide dispersed steels or Li-ion batteries with controlled properties for extreme environmental applications.
\end{abstract}

Key words: advanced materials, extreme environments, hydrothermal synthesis, fast sintering, coatings, ODS, Li-ion batteries.

\section{Introduction}

Development and understanding of materials under extreme environments open new opportunities in every area of technology such as automotive and aerospace, energy generation and storage, electronics, biomedical, chemical and photochemical, metallurgy and machining tools, etc. New processing methods enabling to produce bulk materials (e.g. spark plasma sintering, field assisted sintering, gel casting) with controlled surface/interface properties have been extensively studied to obtain different materials solutions required in many fields of application. Complex systems such as Nano-laminates, Nano-composites (granules, fibers, whiskers, nano-plates reinforced, nano-whiskers reinforced) and oxide dispersion strengthen steels (ODS) systems have been succesfully developed for solar power systems, parts working under high corrosion and erosion, friction parts for automotive or cutting tools [1-11]. On the other hand, modern coatings methods (physical, chemical, electrochemical and combined) feature advantages such as: versatility of materials range to be coated, properties independent of thermodynamic compositional constraints, the ability to control defects states and concentrations, the controllable production of different microstructures and morphologies (including nanosized architechtures), the ability to accommodate large residual strains associated with thermal cycles, ecological benefits and reduced critical raw materials consumption [12, 13].

\section{The Virtual Center SUPERMAT}

Reaching the intrinsic limit of materials performance requires mainly:

a deeper understanding of the atomic and molecular origins on how the extreme environments affect the underlying physical and chemical processes that occur in the bulk and surfaces of different material systems;

- new methods for obtaining and characterising innovative bulk or coating materials systems, leading to the rational utilisation of critical materials in the form of thin films and coatings for application in sensors and novel energy solutions.

A novel integrating approach is needed to focus the research in a multidisciplinary approach that will be briefly presented below. The SUPERMAT virtual centre developed by 7 Research Centres from France, Spain, Italy, Sweden, UK and Romania with recognised expertise in advanced materials and processing technologies has been created to foster the progress in these fields. The activities of this 
virtual centre will focus on the following main directions:

$>$ improving existing modelling and simulation tools for ab-initio design of novel multifunctional materials for extreme environments

$>$ select case studied materials with high application potential

$>$ propose best available technologies (coatings \& sintering) for selected materials

$>$ elaborate characterisation methods to be certified for future standardisation

$>$ propose the European curricula for $\mathrm{PhD}$ students in the field of materials for extreme conditions

$>$ propose joint collaborative research projects for H2020 calls as well as contributing to the strategy of European Technological Innitatives Nanofutures and Critical Raw Materials.

\section{Modelling of smart materials for extreme environmental applications}

Molecular dynamics and computer simulations have significantly contributed to the understanding of damage processes in materials in different environments, over all time- and length- scales, thus opening new opportunities for developing new materials with tailored properties to withstand thermo-mechanical extremes [14]. Numerical modelling for the analysis of multilayered coatings at individual length scales (Continuum, Molecular and Nano-scale, as well as multi-scale) has been reported. Examples include Finite Element Method (FEM), Molecular Dynamics (MD), first-principles calculations and multi-scale modelling [15]. The key features of modelling approaches are based on enabling prediction of processes at different 3D microstructure scales (from meter to micrometer and nanometer) vs. manufacturing history. Moving from macroscale to microstructure, atomic and electronic structure require a multidisciplinary approach involving physics, chemistry, materials science and engineering.

In the specific case of materials under extreme environments, the rational design of phase distribution vs. different external parameters (temperature, pressure, radiation....) requires generating and managing materials databases for specific technological and industrial applications. An example is the NIMS Materials Database [16] and Genome Materials [17] existing at International Centre for Critical Raw Materials including and improving nuclear materials and molten salts properties. The SUPERMAT Consortium will be focused on developing modelling methods related to structural alloys and coatings to predict the final properties based on processing-structure and structure-properties relationships. Fig. 1 presents the modelling approach for structural alloys pilot.

\section{Integration of soft chemical procedures for synthesis of sintered refractory doped oxides}

Different mechanical, physical and chemical processes have been developed for obtaining nanomaterials with controlled chemical composition, structure and morphology. As it was shown before, there is a strong relationship between synthesis and processing routes and the materials properties. In the SUPERMAT project, IMNR is developing different high refractory oxides based on hydrothermal method at temperatures under $250^{\circ} \mathrm{C}$ and pressures under $200 \mathrm{~atm}$. The main advantages of these processes are: controlled homogeneous nucleation of crystalline nanopowders without any thermal treatment, avoid un-controlled grain growth, low energy consumption due to low temperatures and elimination of any thermal treatment for crystallization, high purity and reduced environmental impact due to working in close systems.

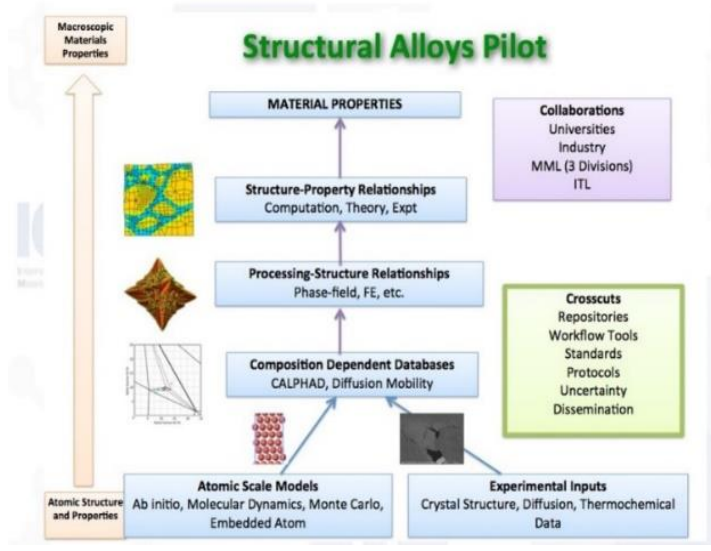

Fig. 1. Modelling approach for structural alloys properties for extreme conditions

As an example, partially stabilized zirconia doped with different rare earth and transitional oxides (Y, $\mathrm{Ce}, \mathrm{Mn}, \mathrm{Gd}, \mathrm{Yb} . . .$. ) for abrasion resistance sintered parts and high temperature functionally graded materials have been obtained by this processes. Thermodynamic prediction using HSC 8 software (allowing chemical reactions and equilibrium calculations based on extensive scientific thermodynamic database) was primary used to evaluate the influence of temperature, $\mathrm{pH}$ and metal activity coefficient on the final composition. As shown in Fig. 2, the use of hydrothermal solutions highly enlarge the $\mathrm{pH}$ stability domain of doped $\mathrm{ZrO}_{2}$. At normal temperatures $\mathrm{T} \leq 100^{\circ} \mathrm{C}$ ) the crystalline $\mathrm{ZrO}_{2}$ is expected to be formed in the $\mathrm{pH}$ range $6.8-10$; the $\mathrm{pH}$ range is extended between 4.5 -10.5 when working in hydrothermal solutions. 


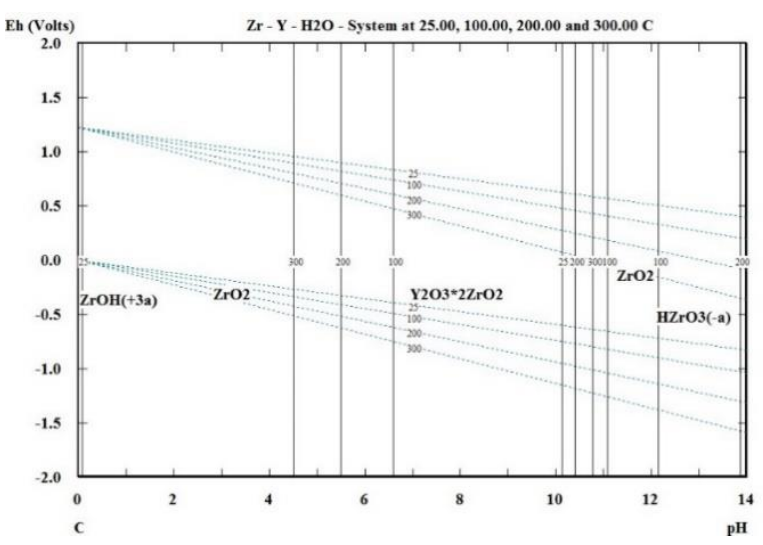

Fig. 2. Thermodynamic prediction of hydrothermal parameters (temperature and $\mathrm{pH}$ ) for the synthesis of doped $\mathrm{ZrO}_{2}$ nanopowders.

As an example, $\mathrm{X}$-ray analysis of $\mathrm{ZrO}_{2}$ doped with 3 mol. $\% \mathrm{Y}_{2} \mathrm{O}_{3}$ and $2 \mathrm{~mol}$. \% $\mathrm{Mn}$ obtained in hydrothermal conditions presented in fig. 3 shows the presence of cubic $\mathrm{ZrO}_{2}$ as major phase $(90.5 \%)$ having an average Scherrer crystallite size $\sim 6.1 \mathrm{~nm}$ and monoclinic $\mathrm{ZrO}_{2}(9.5 \%)$ with an average Scherrer crystallite size $\sim 4.1 \mathrm{~nm}$. The properties of hydrothermally synthesised partially stabilized doped zirconia for further processing by sintering may be strongly improved by integration of hydrothermal synthesis and spray drying to enhance flowability of nanopowders due to obtaining of round shape particles with controlled granulometric distribution below $50 \mu \mathrm{m}$ (Fig. 4).

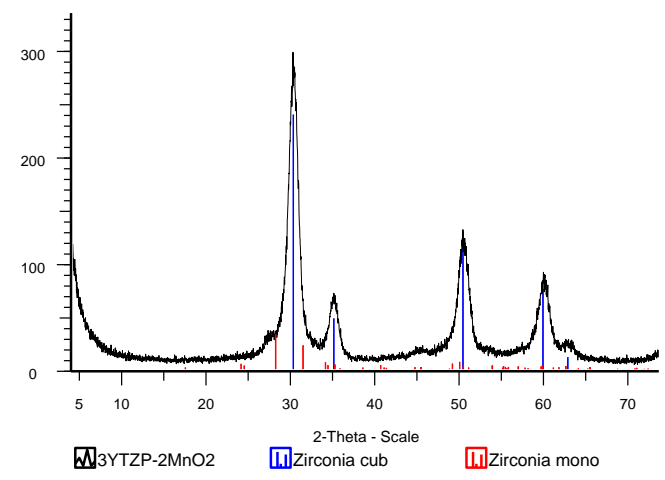

Fig. 3. XRD spectra of $2 \mathrm{~mol} \%$ Mn-yttria doped $\mathrm{ZrO}_{2}$

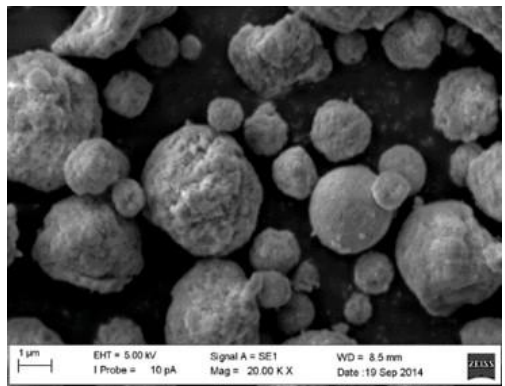

Fig. 4.SEM image of spray dried of 2 mol. $\%$ Mn-yttria doped $\mathrm{ZrO}_{2}$
Another advantage is elimination of undesired nanosized particles with possible un-desired impact on safety conditions during processing.

These powders have been further integrated in a micro-manufacturing process based on a combination of electrical Field Activated Sintering Technology and Micro-Forming for direct manufacture of functional components from supermaterials at University of Strathclyde. The basic principle of this fully integrated sintering processes (shortly named Micro-FAST) is presented in Fig. 5. Process analysis and experimental parameters may be used to predict the sintering regime as shown in Fig. 6. The main advantages are: may be used for a wide range of materials, no need of sintering additives, very short sintering times, lower forming temperatures, maintaining the initial nanostructures of powders, easily controlled process, obtaining of samples with various shapes and sizes.

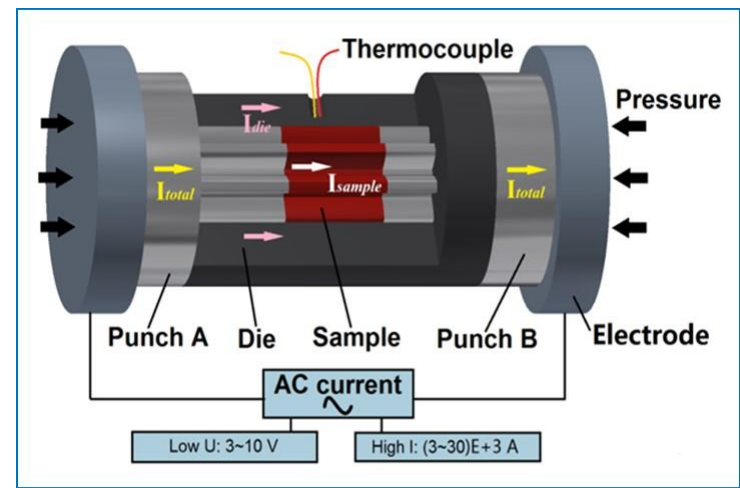

Fig. 5. Micro-FAST sintering system

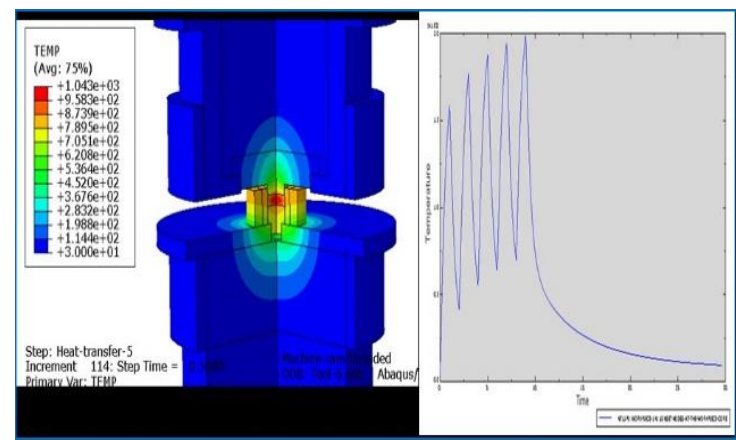

Fig. 6. Process analysis and experimental parameters

\section{Powder metallurgical approaches for developing oxide dispersed steels (ODS) for energy applications}

Powder metallurgy remains a unique method for developing novel composite materials with diverse phase composition by mechanical alloying. The objective of the researches done by ENEA Rome and KTH Stockholm is to optimize powders characteristics by easier, faster and less expensive method for nano-oxide distribution in ODS. An important criterion is to use the grain size 
distribution as an indirect index of nano-dispersion distribution in the steel matrix. The proposed analytical approach is used as screening tool for milling parameter optimization. The experimental system integrates vacuum and normal atmosphere annealing equipment, sample preparation systems and FEG-SEM LEO 1530 and STEM attachment with special software for resolving dislocations and sub-micronic grains. ODS microstructure regions with lower nano-oxide concentrations after milling will experience dislocation recovery and grain growth during consolidation at different temperatures and times. An example is given in Fig. 7 for mechanical alloying of steel with $14 \% \mathrm{Cr}$.

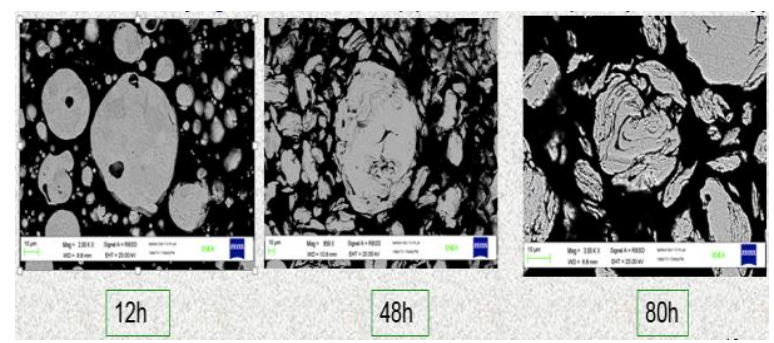

Fig. 7. SEM analysis of steel with $14 \% \mathrm{Cr}$ at different mechanical alloying times

The analysis provides very accurate exploration of grain size distribution and sub-micron domains (crystallites) as well as mapping of ODS powders, over-laid onto SEM of etched ODS powders (Fig. 8).
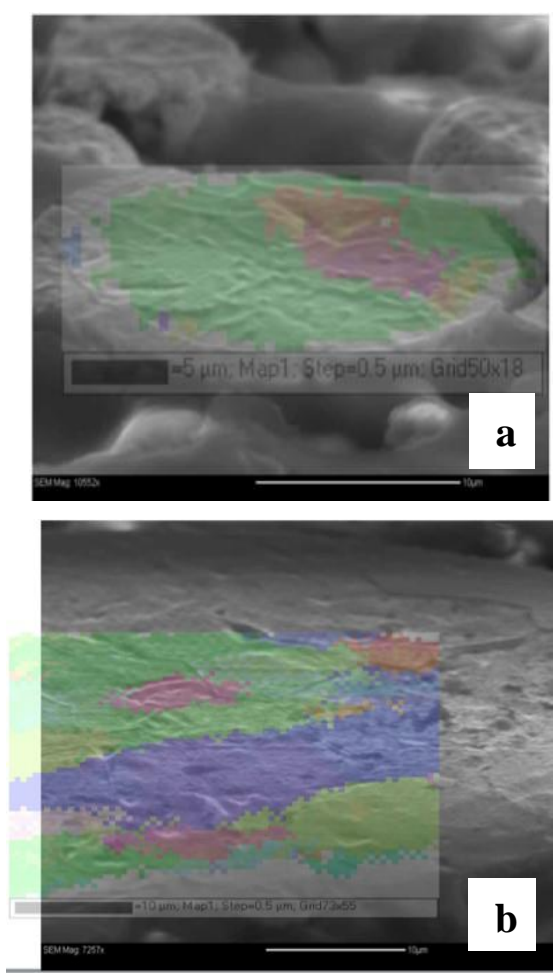

Fig. 8. EBSD mapping of ODS powders overlaid onto SEM of etched ODS powders for small particles (a) and large particles (b) respectively

\section{Novel Li-ion batteries under extreme conditions}

Li-ion batteries represents the ultimate generation of energy storage sources for aeronautics, aerospace, Emobility or portable rechargeable electronic devices. Development and implementation of novel material technology solutions requires specific tests including electric stress (short circuit, abnormal charge...), mechanical stress (impact, crush, shock, drop, penetration...) and gas release analysis. The unique testing facilities from CEA-LITEN Grenoble consist in testing benches (electrical benches, combined testing benches, dropping materials, pneumatic stamping), measurement and registration capabilities (HD cameras, thermal cameras, probes, sensors...) and specific analytic devices (FT-IR, RMN, GC-MS, $\mathrm{X}$-ray...) to study the stability of Li-ion batteries under extreme conditions (Fig. 9a,b).

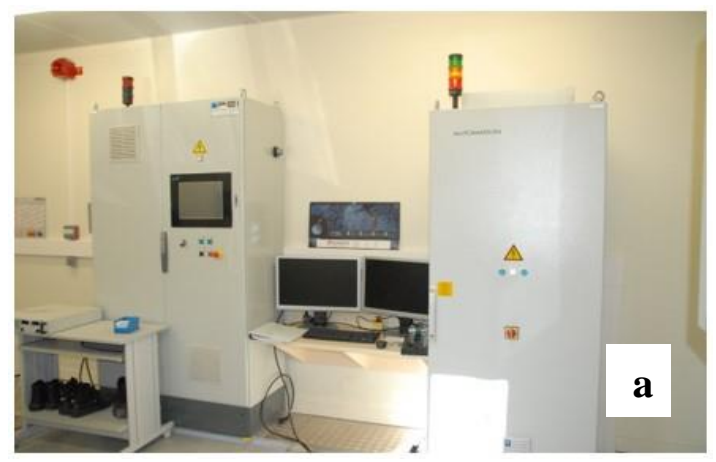

Fig. 9.a. Li-ion batteries measurement system

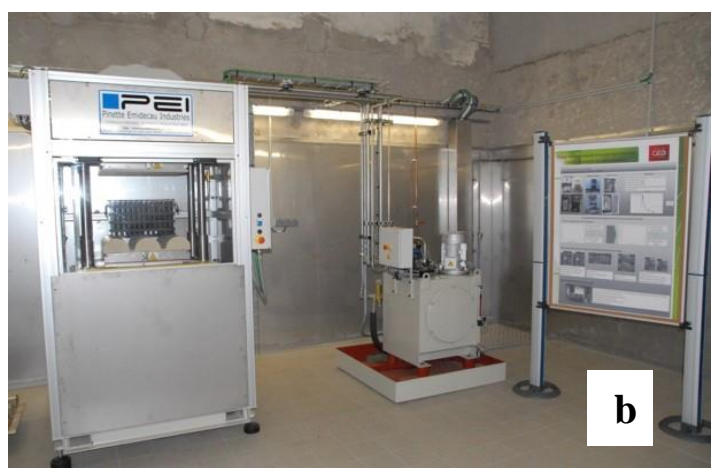

Fig. 9.b. Mechanical testing equipment

\section{Conclusions and future works}

The SUPERMAT Virtual Centre will be a unique network aiming to open new directions in understanding of materials under extreme environments and offering knowledge transfer and technological services for the needs of many high tech industrial domains at Regional and European level.

Different modelling and simulation tools are available and may be further improved to be used in rational design of metallic, ceramic or composite 
materials supporting high environmental mechanical, chemical and radiation stresses.

Novel coating technologies are under development to reduce the use of critical raw materials. Near net shape sintering has been developed to address the needs of mechanical precision equipment requirements.

The virtual centre may cover a wide range of materials for such extreme environments.

\section{Acknowledgement:}

All authors acknowledge the Grant Agreement 692216 SUPERMAT receiving funding from the European Union's Horizon 2020 research and innovation programme.

Prof. Yi Qin and Dr. Radu-R. Piticescu acknowledge also the Grant Agreement 608720 MicroFAST, receiving funding from the European Union's Framework 7 Programme.

Dr. Radu-R. Piticescu, Dr. Antonio Rinaldi and Dr. Santiago Cuesta Lopez acknowledge also COST Action CA 15102 Solutions for Critical Raw Materials under Extreme Conditions.

\section{References}

1. J. Engkvist, S. Canovic, K. Hellström et al., Oxidation of Metals 73, 233-253 (2010)

2. N. Sallez, et al., Acta Mater. 87, 377-3 (2015)

3. E. Zapata-Solvas et al., J Eur. Ceram. Soc. 33, 1373-1386 (2013)

4. J. Lin et al., Mater. Charact. 95, 272-277 (2014)

5. R. He et al., Mater. Design 47, 35-40 (2013)

6. R. He et al., Ceram. Int. 38, 5411-5418, (2012)

7. J. Lin et al., Materials Characterization 95, 272277 (2014)

8. C. Carney et al., J. Eur. Ceram. Soc. 34, 10451051 (2014)

9. M.-H. Chuang et al., Acta Mater. 59, 6308 6317 (2011)

10. Y. Zhang et al., Progress Mater. Sci. 61, 1-93 (2014)

11. Materials Science Forum (2010), doi:10.4028/www.scientific.net/MSF.631632.73

12. Handbook of Deposition Technologies for Films and Coatings, ed. Peter M. Martin, $3^{\text {rd }}$ ed., Elsevier 2010, ISBN-13:978-0-8155-2031-3

13. S. Georgiou, J. Kusinski, P. Dosta, R.R. Piticescu, J.P. Celis et al, Appl.Surf.Sci., 275, 142-147 (2013)

14. D.R. Clarke, C.G. Levi, Ann.Rev. Mater. Res. 33, 383-417 (2003)

15. Structural Materials under extreme Conditions, workshop Los Alamos National Laboratory, 2931 July 2009

16. http://mits.nims.go.jp/index_en.html

17. https://mgi.nist.gov 